\title{
Analysis on the Application of Computer Technology in Water and Soil Conservation Monitoring in Production and Construction Projects
}

\author{
Daoming-CAI ${ }^{1, a}{ }^{*}$ and Wensheng-XU ${ }^{2, b}$ \\ ${ }^{1.2}$ Department of Soil and Water Conservation, Changjiang River Scientific Research Institute, \\ Hubei province, 430010, China \\ acdm1528@126.com, ${ }^{\mathrm{b}} \mathrm{cdm}$ china1983@hotmail.com
}

\begin{abstract}
Keywords: Computer technology; Production and construction; Water and soil conservation; Monitoring; Application
\end{abstract}

\begin{abstract}
With the development of computer technology in our country, the cost is further reduced and the running speed is greatly improved. Graphics processing and display functions increasingly powerful, the use of more widely used in various fields. Obviously, from the life of human society to work already cannot do without the figure of the computer, the computer intelligent, automation and other characteristics, can effectively improve the work efficiency, so it is in the field of soil and water conservation. According to the report of soil and water conservation plan approved by the competent department of the administrative department, the production and construction department will select the appropriate method of soil and water conservation, thereby preventing more serious soil erosion phenomenon, in order to protect the ecological environment. In this process, combined with the appropriate computer technology to use specific monitoring measures, the production and construction projects to perform real-time monitoring of soil and water conservation methods to launch real-time monitoring, the effect is more significant. The main work of soil and water conservation in production and construction projects in detail, then the computer analyzes application in production and construction projects for soil and water conservation monitoring, to provide the reference for related practitioners.
\end{abstract}

\section{Introduction}

Since the age of steam and the industrial age, the world is now in the development of the information age, and the information age is the most important to rely on computer development. Along with the development of computer technology in our country, the cost is further reduced, the running speed is greatly improved, the graphics processing and display function is becoming more and more powerful, and it is widely used in various fields. From the life of human society to work already cannot do without the figure of the computer, the computer intelligent, automation and other characteristics, can effectively improve work efficiency, achieve the past manual work to do the task. This is also true in the field of water and soil conservation. The man-made soil and water loss caused by various kinds of production and construction projects is becoming more and more serious, which brings a lot of harm to the human living environment. Time not balanced and sudden, high strength and great harm to the production characteristics of construction project of soil and water conservation monitoring as an important starting point to prevent soil erosion. With the rapid development of social economy, the phenomenon of man-made soil erosion by the production of all types of construction projects have become increasingly prominent, brought to the human environment problems are increasing, especially water pollution, destruction of farmland, drainage facilities and other hazards. This requires the production of construction department to select appropriate methods of soil and water conservation scheme according to the report of water administrative departments approved to maintain, so as to prevent the phenomenon of more serious soil erosion, in order to protect the ecological environment. In this process, combined with the appropriate computer technology to use specific monitoring measures, the production and construction projects to perform real-time monitoring of soil and water conservation methods to launch real-time monitoring, the effect is more significant. 


\section{Current Situation of Water and Soil Conservation Work in Production and Construction Projects}

China's vast territory, diverse ecological environment, but because in this piece of land to live too long, on this piece of land has also caused great damage. Especially before and after the reform and opening up, the most serious ecological destruction. Before the reform and opening up, Chinese people are lack of awareness of environmental protection, the castle became barren hills, green water into the sewage. And after the reform and opening up, in order to develop the economy, to destroy the ecological cost, large-scale development of the economy, resulting in serious soil erosion, serious ecological damage. In the past ten years, with the development of economic level, and the continuous improvement of people's awareness of environmental protection, to strengthen the ecological protection, prevention and control of water and soil loss awareness.

Lack of Overall Importance. Due to the low level of economic development in the past, the main focus is on economic development, so the development of the work of soil and water conservation. As for soil and water conservation monitoring and forecasting work started even later. Therefore, compared with the current situation of soil and water loss in our country, the monitoring work of the production and construction project is relatively backward. Although our country in recent years has been increasing on monitoring the propaganda work of soil and water conservation in production and construction projects, to actively implement the production units, but the general effect, the whole work is hindered. Therefore, this requires the Chinese government at all levels of the water administrative departments can effectively put the specific relevant policies and regulations in detail to carry out a thorough. At the same time improve the propaganda, strengthen the supervision of public opinion, but also strengthen the consciousness of protecting ecological environment of the enterprise, so the development of enterprises to consciously pay attention to soil and water conservation work, and actively carry out the work. Of course, only by virtue of corporate consciousness is not enough, but also need the government through administrative policies and economic incentives to guide enterprises to carry out the work.

Single Monitoring Method. At present, the monitoring methods adopted in this industry are mainly based on the ground observation and survey. The main use of ground monitoring simple plot drilling method, and for monitoring the development of soil and water conservation project. Because the monitoring time is not long, and complex surface conditions, with a variety of conditions, micro topography changes frequently, coupled with the lack of funds for monitoring, the monitoring work is hindered, resulting in soil erosion monitoring method is simple, accurate monitoring data of cross data have error is not small, so as to the actual soil keep the work brought no small difficulty. According to the present situation of monitoring method is single, authorities need to be from a technical point monitoring method of production and construction units to provide effective guidance, monitoring method of science, to strengthen the monitoring of accurate data, the development and construction units to carry out to provide reliable data and reference to the management of soil and water conservation. Of course, the development and construction units may not always expect the authorities to help; this will give the authorities to bring too much burden of work, or the need to find ways to solve the problem of the single monitoring method, as far as possible to enrich the monitoring means.

\section{Application of Computer in the Monitoring of Water and Soil Conservation in Production And Construction Projects}

Overall Implementation of Monitoring Objectives. Around the full realization of the monitoring objectives, to achieve this goal, we need to establish and improve the database management information system, to ensure that the database has enough data support. At present, the database management information system is the new development of the intelligent database system (IDS), this system is added to the original database in the new data, to start a new organization or arrangement of all the data, ensure the accuracy of data query and processing and fast degree. After the combination of computer use, the rules and regulations of management system through the form 
of performance, the overall idea of using the integration process, play a role, to establish a "system of rules, the management mode of the referee" system, the system requires the use of methods of process optimization show. At the same time, the use of system construction will be fixed, so that the continuity of the system construction and not to be determined, the past by the artificial supervision work, replace the computer connected to the system of supervision. In addition, it can also make each transaction running in the system under the supervision of each resource will be operated in the monitoring system, so it does not appear to place his tricks or in private transactions, to ensure the purity of each business link. At the same time, the rational use of high-tech computer technology, can effectively prevent and correct clean, not standardized, not responsible for other administrative issues, so as to ensure the rational allocation of each resource, to ensure the fairness and justice of power use.

Overall Use of Monitoring Procedures. Combined with modern computer use, monitoring of soil and water conservation through data processing, using mathematics and graphics rendering approach to handle the production and construction process, from the beginning of the production construction project monitoring the implementation of the preparation stage, and in accordance with the project with clear wake up scientific and effective monitoring the implementation method of preparation. At the same time to organize the related staff, equipment's, technology, distribution and advance management team, technical team and organization management content needs, so as to promote the follow-up work smoothly. To carry out monitoring work, to effectively abide by monitoring the implementation of programs start monitoring for each production and construction projects, like must according to embodiments set the frequency of monitoring the implementation of on-site monitoring. At the same time each site monitoring should be completed in a timely manner by a dedicated record of personnel records, and then by the review of personnel, production and construction unit staff to sign. Monitoring after the end of the work, and the need of monitoring work of soil and water conservation plan approval together, and also by the expert group review, if not through the review also need to fight back to continue to monitor, to ensure the good development of soil and water conservation work. Determine the monitoring procedures, the above mentioned system, effectively regulate the monitoring procedures, to ensure the accuracy of monitoring data, strengthen the reliability of monitoring text, has greatly promoted the progress of the monitoring work of soil and water conservation in production and construction projects, so as to strengthen the management of soil and water conservation in production and construction projects.

Comprehensive Upgrade of Monitoring Methods. The combination of computer technology can select different ways like inquiry, data collection, survey, so as to carry out comprehensive refinement on Soil in production and construction to maintain understanding, effectively grasp the details of the work of soil and water conservation, so as to the implementation and follow-up monitoring method of soil and water conservation work and the future work of soil and water conservation continue to provide a reliable reference. In addition, it is also able to combine the most advanced monitoring technology, such as DATAMINE, SURPAC and LYNX, etc. In the actual use of the process, these systems are generally used in software and CAD Auto software is used to enhance the graphics display processing. By using a reference monitoring method, which is to select the significant colleagues fixed reference, including walls, floor, stone and other objects, the use of paint to mark nicks, the first layer position. At this location based on time on soil deposition or soil erosion thickness on real-time monitoring, and accurate records, so as to assess the catchment area in the soil erosion situation and soil erosion modulus. Of course, it can also choose field detection method, which is in each production construction projects are carried out monitoring of soil and water conservation, monitoring personnel are required on time or at least once to the scene to conduct field monitoring, and timely access to first-hand accurate data. If the monitor cannot visit the scene of their own mobile phone data, then the acquisition of second-hand data will affect the normal development of the follow-up work. As is the use of GPS, laser rangefinder, leveling instrument, can effectively on the slag field area, slag height, soil and water conservation measures on layout of real-time monitoring, colleagues timely record, to ensure the accuracy of monitoring data. 
Detailed Application of Monitoring Content. In addition, the staff report, supervised the compilation of the text, analysis of the condition monitoring work cannot be ignored, there is a need for precise analysis of the data, to form a detailed report style, so as to improve the status of production and construction project of soil and water conservation work carried out to provide services.

The specific use of computer information technology, the intelligent computer software and traditional computer software can combine the actual monitoring content is more detailed grasp, so as to accurately understand the work of soil and water conservation, to ensure the follow-up work smoothly. But in the actual work process, according to the continuous refinement of the specific content of monitoring, to determine the distribution of related equipment, monitoring personnel preparation, technical means and monitoring frequency technology specific content, so as to strengthen the monitoring work off, ensure the quality of work and precision, so as to guarantee the production and construction unit of soil and water conservation work. In addition, the topography changes to the project area, such as the change of land use situation in real-time monitoring, and monitoring on the basis of the fundamental reasons of soil erosion for production and construction projects, and to collect real-time data storage. Then the calculation, induction and summarization are carried out, which provide reference experience for the future work of monitoring and soil and water conservation. Before the monitoring work, need according to the actual needs of monitoring, the implementation of the program, the production of construction project acceptance test report and other related content as much as possible so as to fully grasp the refinement, monitoring the situation, also need regular staff to start monitoring technology training, and to the field of training, to strengthen the monitoring of workers' quality of work.

\section{Conclusion}

Today's era is the information age, and the information age is the most important is the computer, the development of the computer has greatly facilitated people's lives, and promote the development of productive forces. Along with the development of computer technology in our country, the cost is further reduced, the running speed is greatly improved, the graphics processing and display function is becoming more and more powerful, and it is widely used in various fields. From the life of human society to work already cannot do without the figure of the computer, the computer intelligent, automation and other characteristics, can effectively improve work efficiency, achieve the past manual work to do the task. So in the field of water and soil conservation. The man-made soil and water loss caused by various kinds of production and construction projects is becoming more and more serious, which brings a lot of harm to the human living environment. Time not balanced and sudden, high strength and great harm to the production characteristics of construction project of soil and water conservation monitoring as an important starting point to prevent soil erosion. According to the report of soil and water conservation plan approved by the competent department of the administrative department, the production and construction department will select the appropriate method of soil and water conservation, thereby preventing more serious soil erosion phenomenon, in order to protect the ecological environment. In this process, combined with the appropriate computer technology to use specific monitoring measures, the production and construction projects to perform real-time monitoring of soil and water conservation methods to launch real-time monitoring, the effect is more significant. Through the analysis of application of computer in soil and water loss in the construction project from many aspects, combined with a variety of scientific and technical means to work around the comprehensive use of technology in all aspects of soil and water conservation, the overall efficiency of the computer can highlight the better, better service for the monitoring work of soil and water conservation production and construction projects, in order to protect our environment.

\section{Acknowledgements}

Projects to promote science and technology from Ministry of Water Resources (NO.TG1518) 


\section{References}

[1] J.Y. Fan: People's Pearl River.Vol, 10 (2016) p.121.

[2] D. Jiang, H. Zhao and M. Zheng: Soil and Water Conservation in China, Vol. 10 (2016) p.246.

[3] K. Chen, B. Liu: Water \& Soil Maintenance in China, Vol. 08 (2013) p.351.

[4] Z. Wang's. Li and Z. Chen:L: China soil and water conservation science, Vol. 06 (2011) p.32.

[5] B.Han: Sichuan Hydroelectric power, Vol. 04 (2008) p.75.

[6] B. Han: Shaaxi Water conservancy, Vol. 03 (2015) p.52.

[7] D. Jiang, Y. Tian and J. Hao: Bulletin of soil and water conservation, Vol. 03 (2015) p.85.

[8] F. Dong and L. Kang: China water and soil conservation, Vol. 03 (2014) p.58.

[9] Q. Zhou: Hebei Water conservancy, Vol. 04 (2014) p.22.

[10] Y. Lv: Modern Agricultural Technology, Vol. 11 (2014) p.56. 